\title{
Reliability analysis of rainwater tanks in Melbourne using daily water balance model.
}

\begin{abstract}
With the aim of developing a comprehensive decision support tool for the performance analysis and design of rainwater tanks, a simple spreadsheet based daily water balance model was developed using daily rainfall data, contributing roof area, rainfall loss factor, available storage volume, tank overflow and rainwater demand. In order to assess reliability of domestic rainwater tanks in augmenting partial household water demand in Melbourne (Australia) area, the developed water balance model was used for three different climatic conditions (i.e. dry, average, and wet years). Historical daily rainfall data was collected from a rainfall station near Melbourne city central. From historical rainfall data three representative years (driest, average and wettest) were selected for the current analysis. Reliability is defined as percentage of days in a year when rainwater tank was able to supply the intended partial demand for a particular condition. For the three climatic conditions, several reliability charts are presented for domestic rainwater tanks in relations to tank volume, roof area, number of people in a house (i.e. water demand) and percentage of total water demand to be satisfied by harvested rainwater. In brief, for a two-people household scenario, $\sim 100 \%$ reliability can be achieved with a roof size of 150-300 m2 having a tank size of 5000-10,000 L. However, for a four-people household scenario, it is not possible to achieve a $100 \%$ reliability, even with a roof size of $300 \mathrm{~m} 2$ and a tank size of 10,000 L.
\end{abstract}

Keyword: Rainwater tank; Daily water balance; Climatic conditions; Reliability and historical rainfall. 